\title{
PENGARUH CITRA DIRI (SELF IMAGE) DAN KONFORMITAS TERHADAP PERILAKU COMPULSIVE BUYING PADA REMAJA
}

\author{
Januar Rohman \\ Akhmad Baidun \\ APIO DKI Jakarta \\ akhmad.baidun@uinjkt.ac.id
}

\begin{abstract}
The aim of this study was to examine the effect of self-image and conformity toward compulsive buying. The samples was 167 teenagers aged 15-18 years who were taken by nonprobability sampling technique. The data analysis which was used was accidental at significance level of 0.05 . the result showed that there is significance effect of self-image and conformity toward compulsive buying among teenagers. This study also showed that $21 \%$ of compulsive buying among teenagers was predicted by self-image and conformity, while the rest were predicted by other variables. Normative conformity, informative conformity, and sex had significant effect toward compulsive buying.
\end{abstract}

Keywords: conformity, compulsive buying, self-image, teenagers

\begin{abstract}
Abstrak
Penelitian ini bertujuan untuk mengetahui pengaruh compulsive buying, citra diri (self image) dan konformitas. Sampel penelitian ini yaitu remaja yang berusia antara 15-18 tahun yang berjumlah 167 remaja. Teknik sampling yang digunakan yaitu non-probability sampling. Analisis data yang digunakan yaitu accidental pada taraf signifikansi 0.05. Hasil penelitian menunjukkan bahwa terdapat pengaruh yang signifikan compulsive buying, citra diri (self image) dan konformitas pada remaja. Proporsi varians dari compulsive buying yang dijelaskan oleh seluruh variabel bebas yaitu sebesar 21\%, sedangkan $79 \%$ sisanya dipengaruhi oleh variabel lain di luar penelitian ini. Hasil uji hipotesis menunjukkan bahwa konformitas normative dan konformitas informative, serta jenis kelamin memiliki pengaruh yang signifikan terhadap perilaku compulsive buying.
\end{abstract}

Kata kunci: belanja kompulsif, citra diri, konformitas, remaja 


\section{PENDAHULUAN}

Bardasarkan hasil riset yang dilakukan oleh AC Nielsen pada tahun 2006, ditemukan bahwa Indonesia adalah negara kedua di Asia yang memiliki penggila belanja terbanyak. Berdasarkan survey lain Singapore Tourims Bords pada tahun 2008, pengunjung terbesar Singapore Great Sale adalah orang Indonesia (Masnia dalam Riyanto, 2014). Dari hasil survei ini dapat disumpulkan bahwa orang Indonesia memiliki tingkat konsumtif yang tinggi dan memiliki kecendrungan pembelian kompulsif.

Compulsive buying merupakan perilaku seseorang yang melakukan aktivitas pembelian berulang. Akibat adanya peristiwa yang tidak menyenangkan ataupun perasaan yang negatif. Jika seseorang memiliki perilaku compulsive buying, maka pada saat menghadapi suatu peristiwa yang tidak menyenangkan atau negatif dia akan melakukan aktivitas pembelian atau berbelanja untuk mengurangi perasaan yang tidak menyenangkan atau negatif tersebut. (Faber \& O`Guinn, 1989)

Fenomena perilaku compulsive buying juga banyak melanda kehidupan remaja di kota besar, yang sebenarnya belum memiliki kemampuan finansial untuk memenuhi kebutuhannya. Remaja memang sering dijadikan target pemasaran berbagai produk industri, antara lain karena karakteristik mereka yang labil, dan lebih materialistik (Asseal dalam Soliha, 2010). Akibatnya dapat mendorong munculnya berbagai gejala dalam perilaku membeli yang tidak wajar.

Compulsive buying yang dilakukan oleh remaja dapat dipengaruhi oleh berbagai faktor. Salah satu faktor yang turut mempengaruhi Compulsive buying remaja terhadap suatu produk adalah pencarian citra diri remaja. Remaja yang kecanduan berbelanja menjadikan barang yang ia beli sebagai simbol dari diri mereka. Jelas, dalam hal ini barang yang mereka beli bukan lagi sebagai pemuas kebutuhan mereka secara material namun mereka jadikan sebagai simbol keberadaan mereka (Koentjoro \& Fitriana, 2009).

Hurlock menyatakan (1999) citra diri merupakan seluruh ide dan perasaan seseorang baik yang berupa ingatan maupun karakteristik personal yang berupa kepercayaan, nilai, dan keyakinan. Diri yang merupakan -akull seseorang yang meliputi dua aspek yaitu actual self dan ideal self. Keduanya tercermin dalam perilakunya, sehingga melalui perilakunya itu citra diri atau gambaran diri orang tersebut akan nampak. Dittmar 
menambahkan (2005) dalam membentuk citra diri terdapat yang namanya self discrepancies., yaitu perbedaan antara bagaimana individu memandang 
dirinya sendiri (actual self) dan apa yang mereka inginkan terhadap diri mereka (ideal self).

Motivasi untuk mengekspresikan citra diri (self-image) sering diungkapkan melalui pembelian barang dan jasa (Sirgy et al, 2007). Seseorang yang melihat dirinya sebagai individu yang stylist, modern, dan dynamic, mungkin akan membeli barang atau jasa yang dianggap memiliki atribut simbolik tersebut. Sebaliknya seseorang yang memiliki self image simplicity dan reliability akan lebih memilih barang atau jasa yang tidak ruwet, mudah dipakai, dapat diandalkan, dan tahan lama.

Perilaku compulsive buying pada remaja juga dapat disebabkan oleh pengaruh eksternal remaja yaitu konformitas. Konformitas terhadap kelompok dapat menyebabkan remaja memiliki perilaku compulsive buying (Park \& Lee, 2005). Sebagian besar remaja mengetahui bila memakai model pakaian yang sama dengan pakaian anggota kelompok yang popular. Maka kesempatan baginya untuk diterima untuk diterima kelompok menjadi lebih besar (Hurlock 1999).

Park dan Lee (2005) menyatakan terdapat dua dasar pembentuk konformitas yang pertama yaitu konformitas normatif, pengaruh sosial normatif ini akan menyebabkan berubahnya perilaku seseorang karena adanya keinginan dari individu untuk dapat memenuhi harapan kelompok agar dirinya tidak ditolak oleh kelompoknya. Kedua ialah konformitas informatif, pengaruh sosial informatif yang didasarkan pada keinginan individu untuk merasa benar, dimana individu akan bergantung pada kelompok sebagai sumber informasi.

Carmen (dalam Hotpascaman, 2008) menambahkan kedua pengaruh tersebut memiliki peranan dalam diri seseorang dalam melakukan proses konsumsi. Pengaruh normatif memiliki peranan pada proses konsumsi terjadi disaat individu mengikuti aturan kelompok, sedangkan pengaruh informatif memiliki peranan pada proses konsumsi terjadi, apabila individu mendengarkan pendapat dari kelompok dalam hal mengkonsumsi suatu produk, individu menjadikan kelompok sebagai acuan dalam merekomendasikan produk yang akan dikonsumsi.

\section{Dependent variable penelitian:}

Compulsive buying. Compulsive buying suatu manifestasi ekstrim dari individu yang mencari perbaikan suasana hati dan peningkatan rasa percaya 
diri dengan membeli produk yang dapat meningkatkan identitas diri individu tersebut (Dittmar, 2005). 


\section{Independent variable penelitian:}

Citra Diri (Self Image). Citra diri adalah suatu gambaran, cerminan, pandangan, dan bayangan yang dimiliki oleh seseorang mengenai dirinya sendiri. Dimana citra diri tersebut sangat berpengaruh terhadap pola pikir dan pola tingkah lakunya dalam kehidupan sehari-hari dalam hubungannya dengan lingkungan sekitar. Dittmar, et al (1995) mengelompokan dimensi citra diri (self image) menjadi dua, yaitu:

1. Actual self image, yaitu bagaimana seseorang melihat dirinya sendiri sebagaimana adanya. Actual self image terbentuk karena adanya citra diri positif dan citra diri negatif pada seseorang.

2. Ideal self image, merupakan konsep seseorang tentang bagaimana mereka ingin dilihat. Dengan kata lain citra diri ideal adalah keinginan seseorang dari apa yang dia inginkan, dan apa yang mereka percaya bahwa mereka bisa.

Konformitas. Konformitas adalah merupakan perubahan sikap dan perilaku individu sesuai dengan standar ataupun harapan yang dibentuk kelompok agar individu dapat diterima dan dipertahankan di dalam kelompok tersebut dan sebagai interaksi yang terjadi di dalam kelompok. Skala konformitas di susun berdasarakan skala konformitas konsumen menurut Bearden, et al (dalam Park \& Lee, 2005), yaitu

a. konformitas normatif, merupakan pengaruh sosial yang didasarkan pada keinginan individu agar disukai atau diterima secara sosial.

b. konformitas informatif adalah pengaruh sosial yang didasarkan pada keinginan individu untuk merasa benar. Individu akan bergantung pada kelompok sebagai sumber informasi.

Faktor Demografis. Demografi dalam penelitian ini adalah jenis kelamin, dan uang saku pemberian orang tua.

\section{METODE}

Populasi penelitian ini yaitu remaja, sedangkan untuk sampelnya siswasiswi Yayasan Islam Syekh Yusuf Tangerang yag berusia 15-18 tahun yang berjumlah 167 siswa. Peneliti memakai teknik Non-probability sampling alat ukur yang digunakan berbentuk kuesioner dengan menggunakan skala model Likert yang telah dimodifikasi menjadi empat alternatif pilihan jawaban yakni, sangat sesuai, sesuai, tidak sesuai dan sangat tidak sesuai. 
Terdapat tiga instrumen pengumpulan data yang digunakan, yaitu skala compulsive buying, skala citra diri dan skala konformitas.

\section{Alat ukur compulsive buying}

Skala compulsive buying berasal dari alat ukur yang dibuat oleh D'Astous, et al (dalam Dittmar 2005), yaitu compulsive buying scale (CBS). Skala ini terdiri dari 11 item dengan aspek Irresistible Impulses, lost control, dan Continuing despite aversive consequences. Hasil uji validitas Confirmatory Factor Analysis (CFA) terhadap masing-masing dimensi, diperoleh model fit Irresistible Impulses dengan nilai Chi-Square $=0.41, \quad \mathrm{df}=2, \quad \mathrm{P}$-value $=0.81564$, RMSEA $=0.000$., kemudian lost control dengan nilai Chi-Square $=0.00, \mathrm{df}=0$, $\mathrm{P}$-value $=1.00000, \mathrm{RMSEA}=0.000$, lalu yang terakhir Continuing despite aversive consequences dengan nilai Chi-Square $=1.40, \quad \mathrm{df}=2, \quad \mathrm{P}$-value $=0.49695$, RMSEA $=0.000$. Dari 11 item yang diuji seluruh item dinyatakan valid.

\section{Alat ukur citra diri (self image)}

Item dalam skala citra diri (self image) dibuat oleh peneliti berdasarkan teori yang dikemukakan oleh Dittmar, Beattie, dan Freise (1995), dimana terdapat 2 dimensi pada alat ukur citra diri (self image) yaitu Actual self image dan Ideal self image. Hasil uji validitas CFA terhadap masing-masing dimensi, diperoleh model fit Actual self image dengan nilai ChiSquare $=35.98, \mathrm{df}=24, \mathrm{P}$-value $=0.05516, \mathrm{RMSEA}=0.055$, kemudian Ideal self image dengan nilai Chi-Square $=35.21, \quad \mathrm{df}=25, \quad \mathrm{P}$-value $=0.08450$, RMSEA $=0.050$. Dari 40 item yang diuji, 35 item dinyatakan valid dan 5 item tidak valid.

\section{Alat ukur konformitas}

Item dalam skala konformitas dibuat berdasarkan alat ukur baku yang dibuat oleh Park dan Lee (2005), dimana terdapat 2 dimensi pada alat ukur konformitas yaitu normatif dan informatif, skala ini terdiri atas 12 item. Hasil uji validitas CFA terhadap masing-masing dimensi, diperoleh model fit normatif dengan Chi-Square $=9.14, \quad \mathrm{df}=6, \quad \mathrm{P}$-value $=0.16568$, RMSEA $=0.056$, selanjutnya informatif dengan nilaiChi-Square $=10.58$, $\mathrm{df}=7$, P-value $=0.15805, \mathrm{RMSEA}=0.056$. Dengan kesimpulan dari 12 item yang diuji, dinyatakan seluruh item valid. 


\section{Teknik Analisis Data}

Untuk melihat pengaruh independent variable I (citra diri), independent variable II (konformitas), terhadap dependent variable (Compulsive buying), peneliti menggunakan teknik statistik Multiple Regression Analysis (Analisis Regresi Berganda). Adapun persamaan analisis regresi berganda pada penelitian ini adalah:

$$
\mathrm{Y}=\mathrm{a}+\mathrm{b}_{1} \mathrm{X}_{1}+\mathrm{b}_{2} \mathrm{X}_{2}+\mathrm{b}_{3} \mathrm{X}_{3}+\mathrm{b}_{4} \mathrm{X}_{4}+\mathrm{b}_{5} \mathrm{X}_{5}+\mathrm{b}_{6} \mathrm{X}_{6}+\mathrm{b}_{7} \mathrm{X}_{7}+e
$$

Keterangan:

Y = Compulsive Buying

a $\quad=$ Intercept (konstan)

$\mathrm{b}=$ Koefisien regresi untuk masing-masing $\mathrm{X}$

$\mathrm{X} 1=$ Actual self image

$\mathrm{X} 2=$ Ideal self iamge

$\mathrm{X} 3=$ Normatif

$\mathrm{X} 4=$ Informatif

$\mathrm{X} 5=$ Usia

$\mathrm{X} 6=$ Jenis Kelamin

X7 = Uang Saku

$\mathrm{e} \quad=$ Residual

Sebelum melakukan analisis regresi berganda, peneliti melakukan korelasi product moment seluruh variabel penelitian. Sebab, dalam regresi idealnya IV tidak berkorelasi dengan IV lainnya, namun justru IV sebaiknya berkorelasi dengan DV.

Selanjutnya analisis regresi dimulai secara simultan, kemudian dari satu per satu IV. Sehingga nilai $\mathrm{R}^{2}$ yang dihasilkan dapat dilihat secara murni. Fungsi $\mathrm{R}^{2}$ ini adalah untuk melihat proporsi varian dari intensi berwirausaha yang dipengaruhi IV yang ada. Melihat jumlah $\mathrm{R}^{2}$ (dikalikan) $100 \%$. Maka dihasilkan proporsi varians atau determinant. $\mathrm{R}^{2}$ sendiri didapatkan dengan rumus:

$$
R^{2}=\frac{\text { SSreg }}{\text { SSy }}
$$


Selanjutnya, untuk membuktikan apakah regresi Y dan X signifikan atau tidak, maka digunakan uji $\mathrm{F}$ untuk membuktikan hal tersebut menggunakan rumus:

$$
F=\frac{R^{2} / k}{\left(1-R^{2}\right) /(N-k-1)}
$$

Dimana pembilang di sini adalah $\mathrm{R}^{2}$ denggan df nya (dilambangkan $\mathrm{k})$, yaitu sejumlah IV yang dianalisis, sedangkan penyebutnya $\left(1-\mathrm{R}^{2}\right)$ dibagi dengan df nya $\mathrm{N}-\mathrm{k}-1$ di mana $\mathrm{N}$ adalah jumlah sampel. Dari hasil uji $\mathrm{F}$ yang dilakukan nantinya, dapat dilihat apakah IV yang diujikan memiliki pengaruh terhada DV.

Kemudian peneliti melakukan uji Tdari tiap - tiap IV yang dianalisis. Maksud uji $\mathrm{T}$ adalah melihat apakah signifikan dampak dari tiap IV terhadap DV. Uji T dilakukan dengan menggunakan rumus sebagai berikut:

$$
t=\frac{b}{s_{b}}
$$

Di mana $b$ adalah koefisien regresi dan $S_{b}$ adalah standar error dari $b$. Hasil uji $\mathrm{T}$ akan diperoleh dengan hasil regresi yang akan dilakukan oleh peneliti nantinya.

\section{Gambaran Deskriptif Sampel}

Sampel yang berjenis kelamin laki-laki berjumlah 41 subjek (24.6\%), sedangkan perempuan berjumlah 126 subjek (75.4\%). Adapun untuk perbedaan usia sampel, yaitu usia 15 tahun 27 subjek (16.2\%), usia 16 tahun 78 subjek (46.7\%), usia 17 tahun 51 subjek (30.5\%), usia 18 tahun 11 subjek (6.5\%). responden dengan uang saku terbesar dalam penelitian ini adalah Rp 150.000-300.000 sebanyak 72 orang atau $43.1 \%$ dari total responden. Responden dengan uang saku Rp 300.001-500.000 berjumlah 62 orang atau $37.1 \%$ dari total responden. Responden dengan uang saku $\mathrm{Rp}$ 500.001-750.000 berjumlah 22 orang atau $13.2 \%$ dari total responden. Responden dengan uang saku Rp 750.000-1.000.000 berjumlah 8 orang atau $4.8 \%$ dari total responden. Sementara responden dengan uang saku lebih dari Rp 1.000 .000 berjumlah 3 orang atau 1.8\% dari total responden 


\section{HASIL}

\section{Hasil Uji Regresi Berganda}

Langkah pertama peneliti menganalisis besaran $R$ square untuk mengetahui berapa persen (\%) varians pada DV yang dijelaskan oleh IV. Untuk tabel $R$ square, dapat dilihat sebagai berikut:

\section{Tabel 1}

Model Summary $R$

\begin{tabular}{lcccc}
\hline Model & R & R Square & $\begin{array}{c}\text { Adjusted R } \\
\text { Square }\end{array}$ & Std. Error of the Estimate \\
\hline 1 & $.458^{\mathrm{a}}$ & .210 & .175 & 8.11266 \\
\hline
\end{tabular}

a. Predictors: (Constant), informatif, uang saku, usia, actual self image, jenis kelamin, normatif, ideal self image

Langkah pertama peneliti melihat besaran $\mathrm{R}$ square untuk mengetahui berapa persen (\%) varians DV yang dijelaskan oleh IV. Dari tabel 1 dapat dilihat bahwa perolehan $\mathrm{R}$ square sebesar 0.210 atau 21\%. Artinya proporsi varians dari compulsive buying yang dijelaskan oleh semua independent variable sebesar $21 \%$, sementara $79 \%$ sisanya dipengaruhi oleh variabel lain di luar penelitian ini.

\section{Tabel 2}

Anova Pengaruh Seluruh IV Terhadap DV

\begin{tabular}{|c|c|c|c|c|c|c|}
\hline Model & & $\begin{array}{c}\text { Sum of } \\
\text { Squares }\end{array}$ & Df & $\begin{array}{c}\text { Mean } \\
\text { Square }\end{array}$ & $\mathbf{F}$ & Sig. \\
\hline \multirow[t]{3}{*}{1} & Regression & 2780.192 & 7 & 397.170 & 6.035 & $.000^{\mathrm{a}}$ \\
\hline & Residual & 10464.634 & 159 & 65.815 & & \\
\hline & Total & 13244.826 & 166 & & & \\
\hline
\end{tabular}

a. Predictors: (Constant), informatif, uang saku, usia, actual self image, jenis

kelamin, normatif, ideal self image

b. Dependent Variable: compulsive buying

Langkah kedua peneliti menganalisis dampak dari seluruh independent variable terhadap compulsive buying. Adapun hasil uji $\mathrm{F}$ dapat dilihat pada tabel 4.12. Jika melihat kolom ke 6 dari kiri diketahui bahwa $(\mathrm{p}<0.05)$, 
maka hipotesis nihil yang menyatakan tidak ada pengaruh yang signifikan dari seluruh independent variable terhadap compulsive buying di tolak. Artinya, 
ada pengaruh yang signifikan dari actual self image, ideal self image, normatif, informatif, usia, jenis kelamin, dan uang saku terhadap perilaku compulsive buying.

Langkah berikutnya, adalah melihat koefisien regresi tiap independen variabel. Jika $\mathrm{p}<0.05$ maka koefisien regresi tersebut signifikan yang berarti bahwa IV tersebut memiliki dampak yang signifikan terhadap compulsive buying. Adapun besarnya koefisien regresi dari masing-masing $I V$ terhadap compulsive buying dapat dilihat pada tabel 3.

Tabel 3

Koefisien Regresi

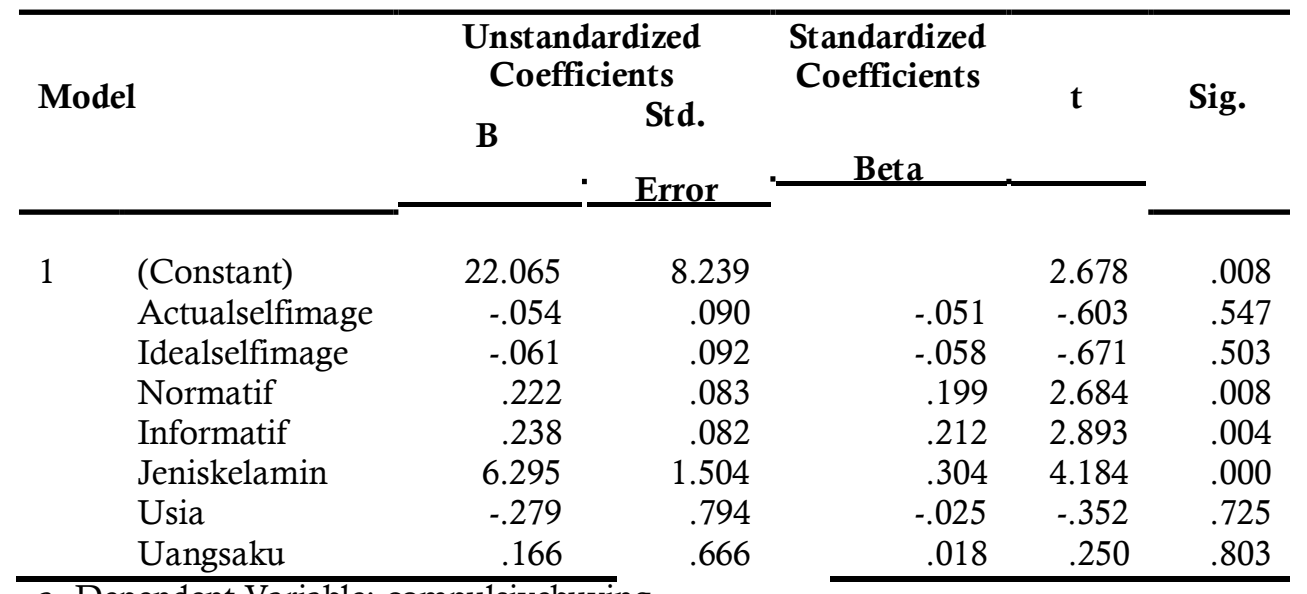

a. Dependent Variable: compulsivebuying

Penjelasan dari nilai koefisien regresi yang diperoleh pada masingmasing $I V$ adalah sebagai berikut:

1. Variabel Actual Self Image

Diperoleh nilai koefisien regresi sebesar -0.054 dengan signifikansi 0.547 $(p<0,05)$, artinya variabel actual self image memiliki pengaruh negatif dan tidak signifikan terhadap perilaku compulsive buying.

2. Variabel Ideal Self Image

Diperoleh nilai koefisien regresi sebesar -0.061 dengan signifikansi 0.503 $(p<0,05)$, artinya variabel ideal self image memiliki pengaruh negatif dan tidak signifikan terhadap perilaku compulsive buying.

3. Variabel Normatif

Diperoleh nilai koefisien regresi sebesar 0.222 dengan signifikansi 0.008 $(p<0,05)$, artinya variabel perilaku normatif memiliki pengaruh positif 
dan signifikan terhadap perilaku compulsive buying. Berarti semakin tinggi normatif semakin tinggi perilaku compulsive buying. 
4. Variabel Informatif

Diperoleh nilai koefisien regresi sebesar 0.328 dengan signifikansi 0.004 $(p<0,05)$, artinya variabel informatif memiliki pengaruh positif dan signifikan terhadap perilaku compulsive buying. Berarti semakin tinggi informatif semakin tinggi perilaku compulsive buying.

5. Variabel Jenis Kelamin

Diperoleh nilai koefisien regresi sebesar 6.295 dengan signifikansi 0.000 $(p<0,05)$, artinya variabel jenis kelamin memiliki pengaruh positif dan signifikan terhadap perilaku compulsive buying. Berarti jenis kelamin mempengaruhi perilaku compulsive buying.

6. Variabel Usia

Diperoleh nilai koesfisien regresi sebesar -0.279 dengan signifikansi 0.725 $(p<0,05)$, artinya variabel usia memiliki pengaruh negatif dan tidak signifikan terhadap perilaku compulsive buying.

7. Variabel Uang Saku

Diperoleh nilai koefisien regresi sebesar 0.166 dengan signifikansi 0.803 $(p<0,05)$, artinya variabel memiliki pengaruh positif dan tidak signifikan terhadap perilaku compulsive buying.

Berdasarkan koefisien regresi di atas dapat dijelaskan persamaan regresi sebagai berikut: ( ${ }^{*}$ signifikan)

$$
\begin{aligned}
\text { Compulsive buying }= & 40.949-(0.054) \text { actual self image }-(0.061) \text { ideal self } \\
& \text { image }+(0.222) \text { normatif }+(0.238) \text { informatif }+ \\
& (6.295) \text { jenis kelamin }-(0.279) \text { usia }+(0.166) \text { uang } \\
& \text { saku }+e
\end{aligned}
$$

Kemudian langkah selanjutnya peneliti menguji penambahan proporsi varians dari tiap variabel independen jika IV tersebut dimasukkan satu per satu ke dalam analisis regresi. Besarnya proporsi varians pada ketangguhan mental dapat dilihat pada tabel 4 berikut: 


\section{Tabel 4}

Proporsi Varians

\begin{tabular}{|c|c|c|c|c|c|c|c|c|c|}
\hline \multirow[b]{2}{*}{ Model } & \multirow[b]{2}{*}{$\mathbf{R}$} & \multirow[b]{2}{*}{$\begin{array}{c}\mathbf{R} \\
\text { Square }\end{array}$} & \multirow[b]{2}{*}{$\begin{array}{l}\text { Adjusted } \\
\text { R Square }\end{array}$} & \multirow{2}{*}{$\begin{array}{l}\text { Std. } \\
\text { Error of } \\
\text { the } \\
\text { Estimate }\end{array}$} & \multicolumn{5}{|c|}{ Change Statistics } \\
\hline & & & & & $\begin{array}{c}\text { R } \\
\text { Square } \\
\text { Change }\end{array}$ & $\begin{array}{c}\text { F } \\
\text { Change }\end{array}$ & df1 & df 2 & $\begin{array}{l}\text { Sig. F } \\
\text { Change }\end{array}$ \\
\hline 1 & $.126^{\mathrm{a}}$ & .016 & .010 & 8.88822 & .016 & 2.655 & 1 & 165 & .105 \\
\hline 2 & $.132^{\mathrm{b}}$ & .017 & .005 & 8.90815 & .002 & .263 & 1 & 164 & .609 \\
\hline 3 & $.241^{\mathrm{c}}$ & .058 & .041 & 8.74865 & .041 & 7.034 & 1 & 163 & .009 \\
\hline 4 & $.341^{\mathrm{d}}$ & .116 & .095 & 8.49908 & .058 & 10.713 & 1 & 162 & .001 \\
\hline 5 & $.457^{\mathrm{e}}$ & .209 & .184 & 8.06671 & .093 & 18.832 & 1 & 161 & .000 \\
\hline 6 & $.458^{\mathrm{f}}$ & .210 & .180 & 8.08886 & .001 & .120 & 1 & 160 & .730 \\
\hline 7 & $.458^{\mathrm{g}}$ & .210 & .175 & 8.11266 & .000 & .062 & 1 & 159 & .803 \\
\hline \multicolumn{10}{|c|}{ a. Predictors: (Constant), actualselfimage } \\
\hline \multicolumn{10}{|c|}{ b. Predictors: (Constant), actualselfimage, idealselfimage } \\
\hline \multicolumn{10}{|c|}{ c. Predictors: (Constant), actualselfimage, idealselfimage, normatif } \\
\hline \multicolumn{10}{|c|}{ d. Predictors: (Constant), actualselfimage, idealselfimage, normatif, informatif } \\
\hline \multicolumn{10}{|c|}{ e. Predictors: (Constant), actualselfimage, idealselfimage, normatif, informatif, jeniskelamin } \\
\hline \multicolumn{10}{|c|}{ f. Predictors: (Constant), actualselfimage, idealselfimage, normatif, informatif, jeniskelamin, usia } \\
\hline
\end{tabular}

Berdasarkan data yang ditampilkan pada tabel 4 dapat dijelaskan bahwa:

1. Variabel actual self image memberikan sumbangan sebesar $1.6 \%$ dalam varians perilaku compulsive buying. Sumbangan tersebut tidak signifikan dengan $\mathrm{F}=2.655$ dan $\mathrm{df}=1.165$.

2. Variabel ideal self image memberikan sumbangan sebesar $0.2 \%$ dalam varians perilaku compulsive buying. Sumbangan tersebut tidak signifikan dengan $\mathrm{F}=0.263$ dan $\mathrm{df}=1.164$

3. Variabel konformitas normatif memberikan sumbangan sebesar $4.1 \%$ dalam varians perilaku compulsive buying. Sumbangan tersebut signifikan dengan $\mathrm{F}=7.034$ dan $\mathrm{df}=1.163$. 
4. Variabel konformitas informatif memberikan sumbangan sebesar $5.8 \%$ dalam varians perilaku compulsive buying. Sumbangan tersebut signifikan dengan $\mathrm{F}=10.713$ dan $\mathrm{df}=1.162$. 
5. Variabel jenis kelamin memberikan sumbangan sebesar $9.3 \%$ dalam varians perilaku compulsive buying. Sumbangan tersebut signifikan dengan $\mathrm{F}=18.832$ dan $\mathrm{df}=1.161$

6. Variabel usia memberikan sumbangan sebesar $00.1 \%$ dalam varians perilaku compulsive buying. Sumbangan tersebut tidak signifikan dengan $\mathrm{F}=0.120$ dan $\mathrm{df}=1.160$.

7. Variabel uang saku memberikan sumbangan sebesar $0.0 \%$ dalam varians perilaku compulsive buying. Sumbangan tersebut tidak signifikan dengan $\mathrm{F}=0.062$ dan $\mathrm{df}=1.159$.

Berdasarkan hasil analisis data penelitian dari koefisien regresi tentang pengaruh citra diri (self image) dan konformitas terhadap perilaku compulsive buying pada remaja, maka hasil kesimpulan yang dapat diambil dari penelitian ini adalah -ada pengaruh yang signifikan citra diri (self image) dan konformitas terhadap perilaku compulsive buying pada remaja.

Dari tujuh variabel independen dalam penelitian ini, hanya ada tiga variabel independen yang signifikan pengaruhnya terhadap compulsive buying yaitu konformitas normatif, konformitas informatif, dan jenis kelamin, dengan demikian hanya ada tiga hipotesis minor yang diterima.

Selanjutnya, jika dilihat berdasarkan proporsi varians setiap variabel juga terdapat tiga variable independen yang signifikan. Variabel tersebut adalah variable konformitas normatif, variabel konformitas informatif, dan variabel jenis kelamin

\section{DISKUSI}

Penelitian ini dilakukan untuk melihat pengaruh variabel internal yaitu citra diri (self image) dan variabel eksternal yaitu konformitas terhadap perilaku compulsive buying. Berdasarkan pengujian hipotesis (minor) yang dilakukan, hanya terdapat tiga variabel yang memiliki pengaruh yang signifikan terhadap perilaku compulsive buying. Variabel tersebut adalah normatif dan informatif, keduanya merupakan dimensi variabel konformitas, serta variabel jenis kelamin. Variabel lain diluar ketiga variabel tersebut tidak memiliki pengaruh yang signifikan terhadap perilaku compulsive buying.

Hasil penelitian dari variabel konformitas, menunjukkan bahwa terdapat pengaruh yang positif dan signifikan pada dimensi konformitas 
normatif terhadap perilaku compulsive buying. Artinya, semakin tinggi konformitas normatif remaja maka semakin tinggi perilaku compulsive buying 
yang dimiliki. Hasil ini sesuai dengan hasil penelitian yang dilakukan oleh Park dan Lee (2005) yang menyatakan konformitas normatif memiliki pengaruh yang signifikan terhadap perilaku compulsive buying. Dengan demikian remaja yang memiliki konformitas normatif tinggi yaitu pengaruh sosial yang didasarkan pada keinginan indivudu agar disukai dan diterima kelompok sosial akan memiliki kecendrungan perilaku compulsive buying yang tinggi.

Alasan mengapa konformitas normatif dapat mempengaruhi compulsive buying remaja karena social cognition pada masa remaja sedang berkembang. Selain itu, Carmen (dalam Hotpascaman, 2008) mengatakan konformitas normatif memiliki peranan dalam proses konsumsi seseorang. Spangenberg et al (dalam Hotpascaman, 2008) menambahkan disaat seseorang menyatakan atau telah melakukan pembelian produk, dikarenakan adanya tekanan atau paksaan dari kelompok, maka disaat itu juga dapat dikatakan bahwa konformitas memberikan peranan penting pada pemakaian atau konsumsi produk.

Hasil penelitian dari independen kedua variabel konformitas, yaitu variabel konformitas informatif. menunjukkan bahwa terdapat pengaruh yang positif dan signifikan pada dimensi konformitas informatif terhadap perilaku compulsive buying pada remaja. Artinya, semakin tinggi konformitas informatif remaja maka semakin tinggi perilaku compulsive buying yang dimiliki. Hasil yang didapat oleh peneliti berbeda dengan hasil penelitian yang dilakukan oleh Park \& Lee (2005) yang menyatakan tidak ada pengaruh konformitas informatif terhadap perilaku online compulsive buying. Peneliti merasa ketidaksesuaian hasil penelitian yang didapat oleh peneliti karena perbedaan lokasi sampel penelitian, dimana sampel peneliti adalah konformitas yang terjadi pada dunia nyata sedangkan penelitian yang dilakukan oleh oleh Park \& Lee (2005) dilakukan pada konformitas virtual. Berdasarkan hasil penelitian yang bersifat positif, dengan demikian remaja yang memiliki konformitas informatif tinggi yaitu pengaruh sosial yang didasarkan pada keinginan indivudu untuk merasa benar, memiliki kecenderungan perilaku compulsive buying yang tinggi. Pengaruh konformitas informatif memiliki peranan pada saat proses konsumsi terjadi, apabila remaja mendengarkan pendapat dari kelompok dalam hal mengkonsumsi suatu produk, maka remaja akan menjadikan kelompok sebagai acuan dalam merekomendasikan produk yang akan dikonsumsi. 
Dari hasil penelitian ini juga didapatkan bahwa ada pengaruh yang positif dan signifikan variabel jenis kelamin dengan perilaku compulsive 
buying pada remaja, Hal ini sejalan dengan penelitian yang dilakukan oleh Faber dan O‘Guinn (1989), dan Dittmar (2005) yang menyatakan bahwa lebih dari $90 \%$ pembeli kompulsif adalah wanita. Namun perbedaan jenis kelamin dalam perilaku pembelian yang kompulsif tidak dijelaskan secara lebih mendalam, hanya ditemukan bukti yang menyatakan bahwa dimensi berbelanja yang terkait dengan masalah emosional dan identitas lebih didominasi oleh konsumen perempuan daripada konsumen pria (Ekowati, 2009).

Dari hasil penelitian didapatkan pula hasil informasi bahwa terdapat empat variabel yang tidak signifikan berpengaruh terhadap perilaku compulsive buying pada remaja, yaitu variabel citra diri (self image) yang terdiri dari variabel actual self image dan ideal self image. Serta variabel demografi yang terdiri dari variabel usia dan variabel uang saku.

Variabel citra diri yang terdiri dari actual self image dan ideal self image keduanya memiliki hasil yang negatif dan tidak signifikan terhadap perilaku compulsive buying. Hasil ini hampir sama dengan hasil penelitian yang diperoleh Hussain et al (2011) tentang pengaruh self image terhadap perilaku impulse buying. Hussain et al (2011) menyatakan self image tidak berpengaruh terhadap perilaku impulse buying. Banyak faktor yang menyebabkan seseorang melupakan citri dirinya dalam pembelian suatu produk (Hussain et al, 2011). misalnya diskon atau potongan harga, sosial ekonomi, keadaan suatu tempat, dan lain sebagainya. Peneliti merasa tidak signifikannya hasil yang diperoleh dalam penelitian ini, dikerenakan keadaan sosial ekomoni sampel dalam penelitian ini adalah kelas menengah ke bawah.

Pada variabel usia dalam penelitian ini didapatkan hasil yang negatif dan tidak signifikan terhadap perilaku compulsive buying. Hasil ini berbeda dengan hasil penelitian yang dilakukan oleh Dittmar (2005) yang menyatakan bahwa usia muda memiliki kecenderungan perilaku compulsive buying yang lebih tinggi. Tetapi secara sistematis tidak ada penelitian yang menyatakan bahwa orang yang berada pada usia tertentu akan cenderung memiliki perilaku compulsive buying lebih kuat dibanding tingkatan usia lainnya (Dittmar dalam ekowati, 2009). Peneliti menganggap perbedaan hasil penelitian ini terjadi karena sampel penelitian ini hanya terfokus kepada remaja, sedangkan sampel penelitian yang dilakukan oleh Dittmar (2005) berasal dari usia remaja dan orang dewasa. Tetapi hasil penelitian yang dilakukan oleh Black et al. (dalam ekowati, 2009) menemukan bahwa perilaku 
compulsive buying merupakan kecenderungan yang terjadi pada mereka yang berusia diantara 30-31 tahun, dan berstatus lajang. 
Untuk variabel uang saku didapatkan hasil yang negatif dan tidak signifikan, itu berarti bahwa variabel uang saku tidak mempengaruhi perilaku compulsive buying. berdasarkan penelitian yang dilakukan oleh Faber dan O‘Guinn (dalam Ekowati, 2009) diketahui bahwa compulsive buying dapat terjadi pada siapa saja dengan tingkat pendapatan yang beragam. Individu dengan tingkat pendapatan yang tinggi juga tidak lepas dari kemungkinan untuk memiliki perilaku pembelian yang kompulsif. Dapat disimpulkan bahwa perilaku compulsive buying dapat terjadi pada siapa saja baik orang yang pendapatannya besar, sedang, maupun rendah. Termasuk didalamnya para remaja yang mendapatkan pendapatannya dari uang saku rendah yang diberikan oleh orangtuanya.

Secara keseluruhan peneliti berpendapat bahwa perbedaan hasil antara hasil penelitian ini dengan penelitian terdahulu dapat disebabkan oleh beberapa hal baik sampel, tempat penelitian, teknik pengambilan data, maupun alat ukur yang digunakan. Pada penelitian selanjutnya, peneliti menyarankan untuk melakukan penelitian dengan tujuan melihat interaksi antar variabel satu dengan yang lainnya sehingga didapatkan kesimpulan yang lebih akurat dan lengkap mengenai variabel yang diteliti.

\section{Saran}

\section{Saran Teoritis}

1. Untuk penelitian selanjutnya, berdasarkan hasil penelitian ini maka peneliti menyarankan untuk mencari faktor lain yang dapat mempengaruhi perilaku pembelian kompulsif, seperti status sosial ekonomi, keluarga, budaya, dan media massa misalnya frekuensi menonton televisi dan iklan yang ditayangkan. Agar didapatkan pengetahuan yang lebih mendalam menganai perilaku membeli kompulsif, Karena patut diduga faktor tersebut memiliki pengaruh terhadap perilaku pembelian kompulsif.

2. Untuk peneliti selanjutnya, sebaiknya sampel yang digunakan adalah subjek yang bervariasi antara sampel yang masih remaja dan sudah dewasa. Karena masa remaja dan dewasa memiliki perkembangan dan kebutuhan yang berbeda, sehingga akan menghasilkan hasil penelitian yang bervariasi.

3. Tidak signifikannya beberapa variabel yang ada dalam penelitian ini diasumsikan berkaitan dengan keadaan sampel penelitian. Oleh karena itu, bagi peneliti selanjutnya yang tertarik untuk melakukan penelitian 
dengan tema yang sama supaya memperhatikan sampel yang akan digunakan.

Dengan memperhatikan saran tersebut, diharapkan penelitian selanjutnya akan lebih menyempurnakan penelitian sebelumnya.

\section{Saran Praktis}

1. Berdasarkan penelitian ini, diketahui bahwa konformitas kelompok teman sebaya, baik itu konformitas normatif maupun konformitas informatif memiliki pengaruh yang signifikan terhadap perilaku compulsive buying. Dari hasil ini, remaja hendaknya lebih teliti dan cerdas dalam bergaul dengan kelompok pertemanannya. Terutama ketika remaja mencoba untuk menyesuaikan diri pada kelompok pertemanan dan menggunakan setiap informasi yang diberikan oleh kelompok tersebut dalam pembelian suatu produk atau jasa. Remaja sudah seharusnya dapat menolak ajakan tersebut apabila perilaku itu cenderung kearah konsumtif, supaya remaja dapat terhindar dari perilaku compulsive buying.

2. Remaja sudah seharusnya dapat mengontrol dirinya dan menyeleksi dalam membeli produk atau jasa mana saja yang menjadpi kebutuhan dan keinginannya. Agar remaja dapat menjadi konsumen yang pintar, sehingga tidak muncul perilaku pembelian kompulsif.

3. Remaja harus bisa mengatur keuangannya, apabila secara finansial seseorang remaja tidak dapat membeli suatu barang yang harganya tidak sesuai dengan batas kemampuan, maka remaja jangan memaksakan untuk membelinya,

\section{DAFTAR PUSTAKA}

Aryani, Gunita. (2006). Hubungan antara konformitas dan perilaku konsumtif pada pemaja di SMA 1 Semarang. Skripsi fakultas psikologi UNS Semarang.

Dittmar H, J Beattie, \& S Friese. (1995). Objects, decision considerations and self-image in men's and women's impulse purchases. ESRC grant No. L122251012, as part of the Economic Beliefs and Behaviour Programme.

Dittmar H. (2005). A new look at -compulsive buyingll: self-discrepancies and materialistic values as predictors of compulsive buying tendency. Journal of Social And Clinical Psychology. 24 (6), 832-859. 
Dittmar, H. (2005). Compulsive buying - A growing concern? An examination of gender, age, and endorsement of materialistic values as preditors. British Journal of Psychology, 96, 467-491.

Ekowati, Titin. (2009). Compulsive buying : tijauan pemasar dan psikolog. Jurnal psikologi.

Faber, R.J. and O`Guinn, T.C. (1989). Compulsive buying: A phenomenological exploration. Journal of Consumer Research, 16, 147157.

Hotpascaman, S. (2008). Hubungan perilaku konsumtif dengan konformitas pada remaja. Skripsi: Fakultas Psikologi Universitas Sumatra Utara.

Hurlock, E.B. (1999). Psikologi perkembangan suatu pendekatan sepanjang rentang kehidupan. Alih bahasa : Istiwidayanti. Jakarta : Erlangga.

Hussain M., Farzand Ali Jan, Khurshed Iqbal, Raheel Manzoor, Rahman.S, Imran. (2011). Do people consider self image in impulse buying behavior in Peshawar, Pakistan? Interdisciplinary Journal of Contemporary Research In Busness. December 2011, 3 (8)

Koentjoro \& Nina Fitriani. (2009). Keranjingan berbelanja pada wanita bekerja. 7 (1). Fenomena: 48-47 ISSN 1693-4296

Park, Jung Kun \& Yun Jung Lee. (2005). The mediating role of consumer conformity in E-compulsive buying. Purdue University, USA. 
